\title{
Influence of fire position on smoke movement in an inner corridor building with multiple openings
}

\author{
Xiaotao Zhang ${ }^{1}$, Lingling Du ${ }^{2}$, Guihong Pei $^{1}$, Lei Zhu ${ }^{1}$,Yue Zhang ${ }^{1}$ \\ ${ }^{1}$ School of Architectural Economics and Engineering Management, Hubei Business College, Wuhan, 430079, China; \\ ${ }^{2}$ School of Civil Engineering and Architecture, Chongqing Vocational College of Transportation, Chongqing, 402247, China;
}

\begin{abstract}
The influence of fire position on the neutral plane height was analyzed in order to analyze the smoke movement. One inner corridor building multiple openings was constructed by computational fluid dynamics (CFD) software and the airflow velocity and the pressure distribution under different fire position. The result shows that the influence of fire position on the height of neutral plane can be divided into two phases and the base height $\left(\mathrm{H}_{\mathrm{b}}\right)$ is put forward as the critical values for the two phases. When the he height of fire $\left(h_{f}\right.$ ) is lower than $\mathrm{H}_{b}$, namely $h_{f}<\mathrm{H}_{b}$, with the $h_{f}$ increasing, the neutral plane height increase is not significant. However, when the $\mathrm{h}_{\mathrm{f}}>\mathrm{H}_{\mathrm{b}}$, with the fire height increasing, the neutral plane height increase significantly. Additionaly, in the condition, the position of neutral plane will be on the same level as that of the fire soucrce.
\end{abstract}

\section{Introduction}

With the rapid development of urbanization, many high-rise buildings have been constructed all over the world. According to the Council on Tall Buildings and Urban Habitat $(\mathrm{CTBUH})^{[1]}$, up to now, 1502 buildings over 200 meters have been constructed in the world, and that number has almost tripled over the past 10 years. At the same time, the number of $200 \mathrm{~m}+$ buildings under construction is 408. Although the development of high-rise building could meet the needs of urbanization, it would increase the difficulty level in fire control. In recent years, the fire accidents break out frequently, which has brought great casualties and economic losses to society. Therefore, the fire safety of high-rise buildings received more and more attention.

Statistics showed that smoke and toxic gases are the most fatal hazard to the people in fires, almost $85 \%$ of the people killed in building fires are killed by toxic smoke ${ }^{[2]}$. Therefore, the movement mechanism of fire smoke in high-rise buildings has drawn increasing attention. Almost of high-rise buildings have vertical shafts, such as stairwells, elevator shafts. When the smoke spread into these vertical shafts, the stack effect will form. At this time, a horizontal plane will appear, where the pressure inside equals to the one outside, which is called the neutral plane ${ }^{[3]}$. Below the neutral plane, the pressure inside a building is lower which leading air flow into the building form the opening in the area. Inversely, above the neutral plane, the pressure inside is higher, and the smoke will flow out. Therefore, the position of the neutral plane is a significant parameter to area affected by toxic smoke

A number of studies have been focused on the calculation and prediction of neutral plane position in buildings in the last decades. Klote ${ }^{[4]}$ assumed a developed calculation model for estimating the height of the neutral plane based on the assumption that the smoke temperature in vertical shafts is uniform. Zhang et al. ${ }^{[5]}$ proposed an improved calculation model, in which the shaft space was divided into two zones, fire zone and inner space and the temperature was assumed uniform in each zone. The prediction result obtained by this method was found to be better in accuracy than Klote's. Xu et al. ${ }^{[6]}$ proposed an improved continuum model based on the assumption which the shaft space was divided multi-zone. Numerical simulations and experiments were carried out to validate the models. Mao et al. ${ }^{[7]}$ developed a new model to calculate the neutral plane height which considered the smoke temperature and the openings size. The prediction result is more accurate than other model by experiments.

Many different models for calculating the height of neutral plane in buildings have been proposed in previous studies. However, in these models, the fire source is assumed on the first floor in building. Few studies have been focused on influence of fire position on neutral plane height. In this paper, a set of numerical simulations were conducted to study the influence of fire location on the height of the neutral plane in an inner corridor building with multiple openings.

\section{CFD simulations}

In this study, the neutral plane height was analyzed based

\footnotetext{
"Corresponding author: smiletao@163.com
} 
on a series of CFD simulations by the FDS software, which was released by the National Institute of Standards and Technology (NIST). In these simulations, different fire locations are considered. The Navier-Stokes equations for fire-driven fluid flow are solved by large Eddy Simulation (LES), which is second-order accurate with respect to space and time differences. The governing equations for smoke flowing in a fire are the conservation laws of mass, momentum and energy. More details on the LES can be found in the references ${ }^{[8]}$.

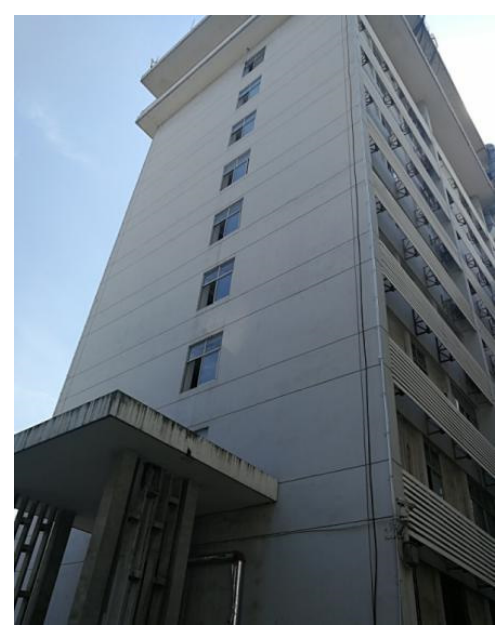

(a)

\subsection{Model configuration}

Fig 1 presents the actual inner corridor building with multiple openings and the model configuration constructed by FDS. The dimension of the modeled building section is $18.2 \mathrm{~m} \times 3.6 \mathrm{~m} \times 27.2 \mathrm{~m}(\mathrm{~L} \times \mathrm{W} \times \mathrm{H})$. Each floor is $3.0 \mathrm{~m}$ high. Since the each door of room should be closed in order to prevent the toxic smoke flow into room, the rooms connect with corridor could be ignored. Each floor has a openings connected with outside and the area is $1.0 \mathrm{~m} \times 1.0 \mathrm{~m}$

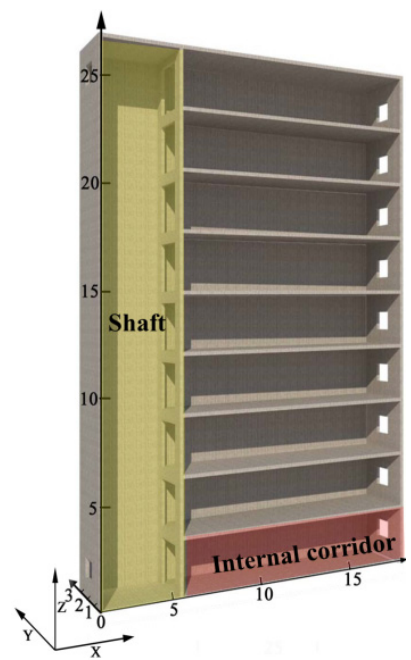

(b)

Fig 1. Model configuration: (a) Buildings with internal corridor; (b) Geometry of simulation model

The distance between the opening and square fire source is $6.5 \mathrm{~m}$ and the length of fire sources is $1 \mathrm{~m}$. According to the Shanghai engineering construction standard-Technical specification for smoke control code, the heat release rate (HRR) in actual building fire is 0.5MW-3.0MW. Considering the most dangerous condition, the HRR of fire is set $3 \mathrm{MW}$ in all CFD simulations. In order to analyze the influence of fire position on the neutral plane height, the fire position are set on the first floor, the second floor, the third floor, the seventh floor and the eighth floor, respectively.

Pr and Sc, together with $\mathrm{C}_{\mathrm{S}}$, are the most important parameters in the simulation of fire-induced transportation of smoke, especially in the prediction of smoke temperature. According to the study by Zhang et.al ${ }^{[9]}$ in FDS simulation, the values of $\mathrm{Pr}, \mathrm{Sc}$ and $\mathrm{C}_{\mathrm{S}}$ are set to be $0.5,0.5$ and 0.18 respectively.

The other details on the simulation settings are summarized in Table 1.

Table 1. CFD simulation settings.

\begin{tabular}{|c|c|c|}
\hline building & $\begin{array}{c}\text { Size } \\
\text { Floors } \\
\text { Environmental temperature }\end{array}$ & $\begin{array}{c}18.2 \mathrm{~m} \times 3.6 \mathrm{~m} \times 27.2 \mathrm{~m}(\mathrm{~L} \times \mathrm{W} \times \mathrm{H}) \\
9 \\
25^{\circ} \mathrm{C}\end{array}$ \\
\hline door & Size & $2.0 \mathrm{~m} \times 2.4 \mathrm{~m}(\mathrm{~W} \times \mathrm{H})$ \\
\hline openings & Size & $1.0 \mathrm{~m} \times 1.0 \mathrm{~m}(\mathrm{~W} \times \mathrm{H})$ \\
\hline CFD & $\begin{array}{c}\text { Grid size } \\
\text { Method of simulation } \\
\text { Dimensions of fire source } \\
\text { Fuel of fire source } \\
\text { HRR of fire } \\
\text { Position of fire }\end{array}$ & $\begin{array}{c}0.2 \mathrm{~m} \times 0.2 \mathrm{~m} \times 0.2 \mathrm{~m}(\mathrm{~L} \times \mathrm{W} \times \mathrm{H}) \\
\text { Large Eddy Simulation }(\text { LES }) \\
1 \mathrm{~m} \times 1 \mathrm{~m}(\mathrm{~L} \times \mathrm{W}) \\
\text { heptane } \\
3 \mathrm{MW} \\
\text { Floor 1, Floor 2, Floor 3, Floor 7, Floor } 8\end{array}$ \\
\hline
\end{tabular}


experimental results in Luo et al study ${ }^{[10]}$, in which the corridor sectional dimension is equal to the simulated model based on the similarity principle. Fig 2 presents the comparison results. From the Fig 2, it is can be seen that the simulation results is good agree with the experiment results which indicates that all the settings in the simulations were appropriate.

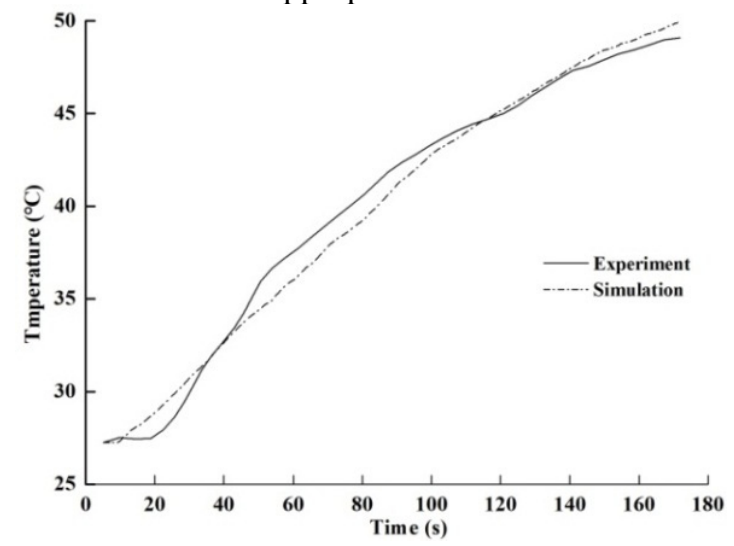

Fig 2. Comparison of smoke temperature

\section{Results and Discussions}

\subsection{Velocity distribution in inner corridors}

When smoke spread into the vertical shafts, the neutral plane forms and the height of that gradually stable. As can be seen from the above, air outside will flow into the building from the opening below the neutral plane and the smoke in building will flow out over the neutral plane. On the neutral plane, the pressure inside equals to the one outside, so the airflow velocity is about equal to zero. Therefore, the neutral plane position can be roughly ascertained by the velocity distribution in building. Taking the $\mathrm{X}$-axis as the positive direction, the airflow velocity curves measured at middle of each opening for different fire position are displayed in Fig 3.

It is can be seen from the Fig 3(a), when the fire is on the floor 1 , the height of the neutral plane is on the floor 5 (hereafter, the height of the neutral plane when fire on floor 1 is called base height, $\mathrm{H}_{\mathrm{b}}$ ). When the fire height $\left(\mathrm{h}_{\mathrm{f}}\right)$ is on the floor 2 and the floor 3 , the height of neutral plane increaze with the height of fire increase, while the increase is not significant. Through observing the postion of the zero velocity line(shown ine Fig 3b and $3 \mathrm{c}$ ), the neutral plane height is not obviously increased and it is still on the floor 5. However, with the continued increasing of the fire position, when the fire is on the floor 7 and floor 8 , the height neutral plane increase significantly. It is can be seen from the Fig 3(d) and (e), when the fire postion is from floor 7 to floor 8 , the neutral plane position increase increase signifanctly.

The above results suggest that the influence of fire position on height of neutral plane can be divided into two phases. When the fire is on the lower floors, the height of neutral plane just increases slightly with fire height increasing. However, when the fire is on the higher floors, with the fire height increasing, the neutral plane height increase significantly.
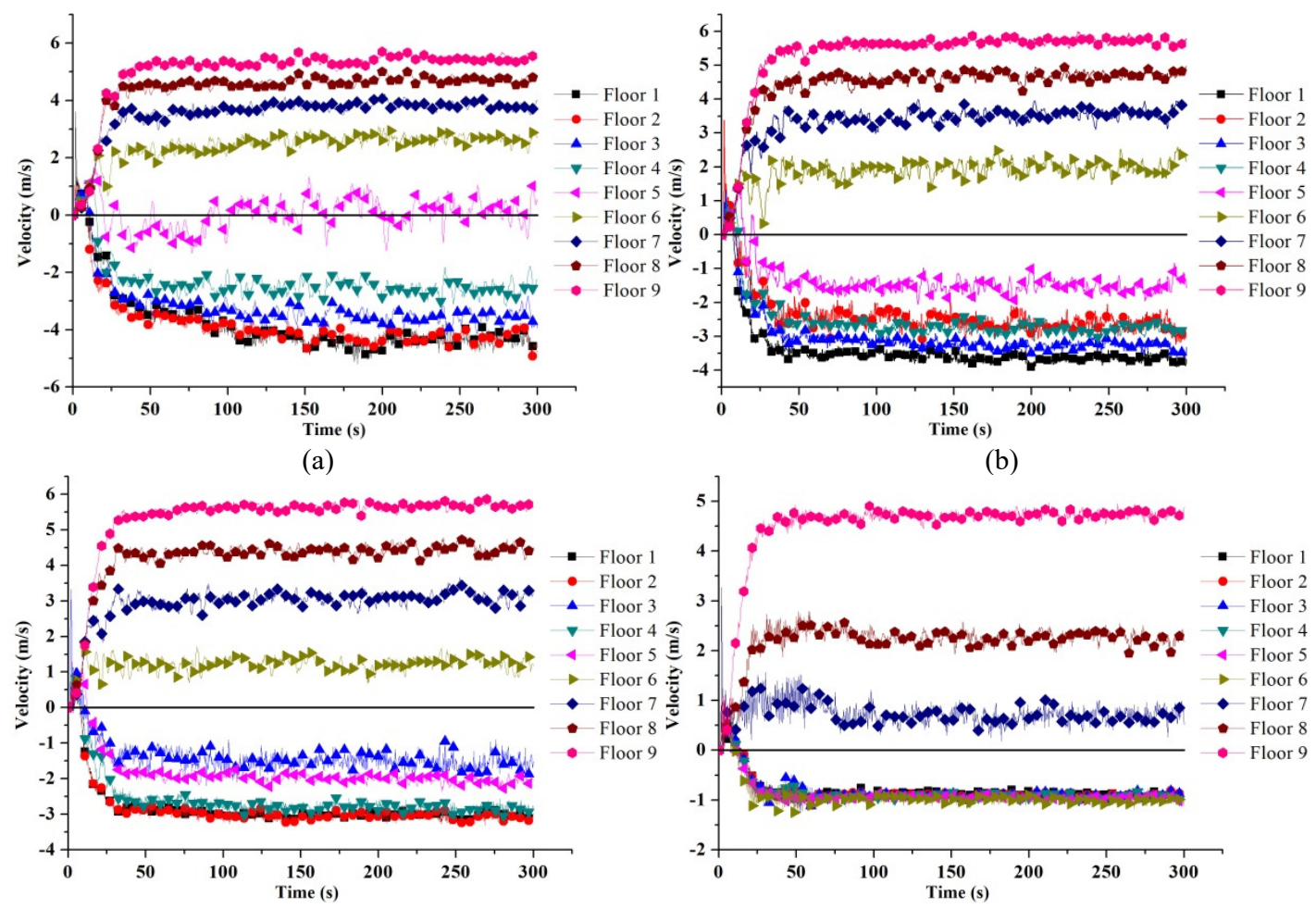

(c) (b)
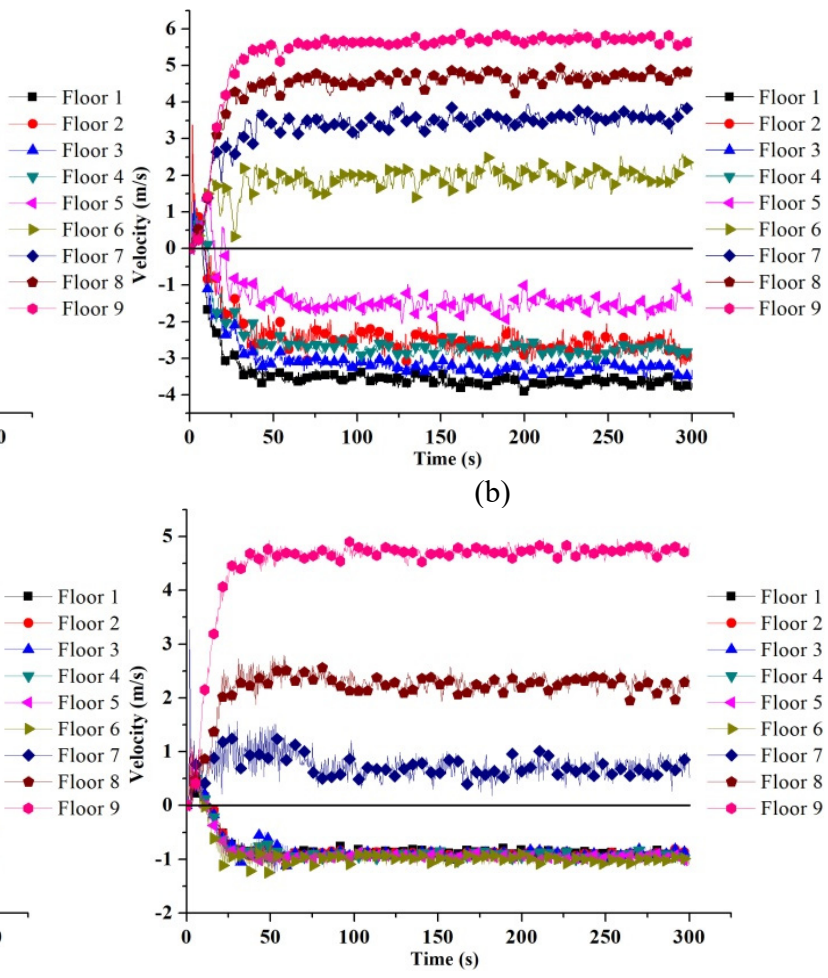

(d) 


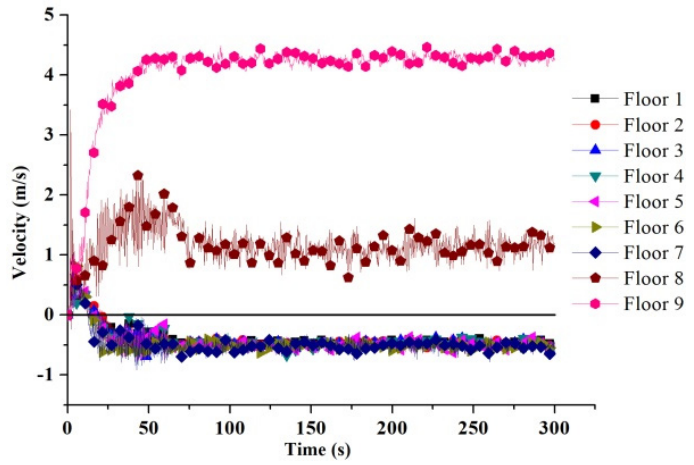

(e)

Fig 3. Velocity of airflow into inner corridor: fire on (a) Floor 1;(b) Floor 2;(c) Floor 3. (d) Floor 7; (e) Floor 8.

\subsection{Pressure distribution in inner corridors}

In the previous sections, the height of neutral plane can be roughly determined through the velocity distribution. But it's not accurate, which lead to the division standard of two phases cannot be clear and definite. As the pressure in neutral plane is equal to zero, the height of neutral plane can be determined by finding the zero pressure plane. To precisely determine the neutral plane height, the pressure distribution is analyzed in the section. Fig 4 presents the pressure contour at middle plane $(\mathrm{Y}=1.8)$ under different fire position. In Fig 4, the red line means that the zero pressure plane which can represent the neutral plane position. It is can be found that some red lines are distributed in the fire floor. That is the neutral plane in fire floor, not the whole building. Therefore, the red lines on fire floor can be ignored. That is not our focus.

As shown in Fig. 4(a), when the fire is on the floor 1 , the height of neutral plane is about $13.6 \mathrm{~m}$, which is on the floor 5. With the fire position changing to floor 2 and 3 (shown in Fig 4b and 4c), the height of neutral plane is about $15.0 \mathrm{~m}$. The position is almost unchanged and it is still on the between floor 5 and floor 6 . It is indicate that in these cases, the height of neutral plane had no significant increase with the height of fire increase. However, when the fire position is on the floor 7 and 8 , the height of neutral plane is $19.4 \mathrm{~m}$ and $22.4 \mathrm{~m}$, respectively, which show that the height of neutral plane increase significantly in these cases.

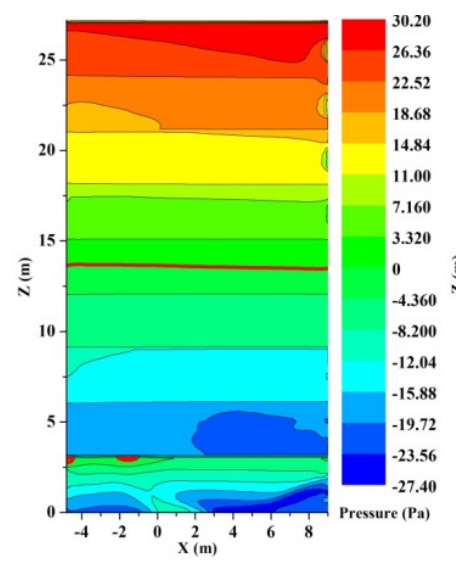

(a)

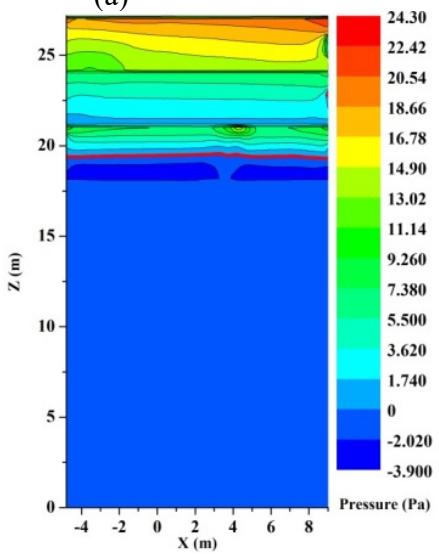

(d)

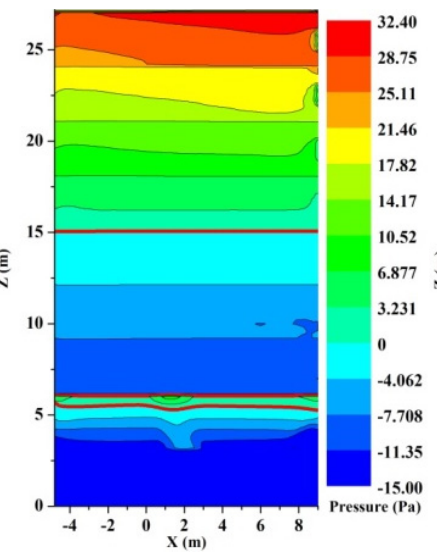

(b)

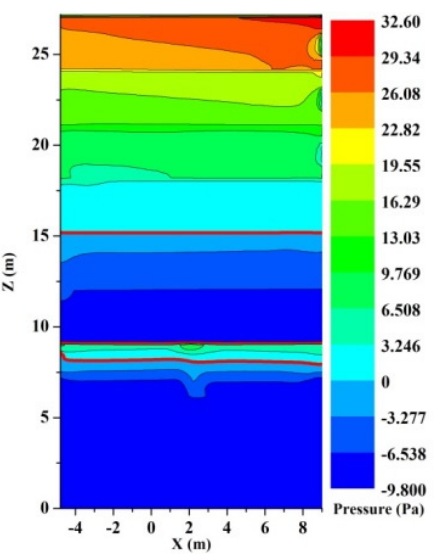

(c)

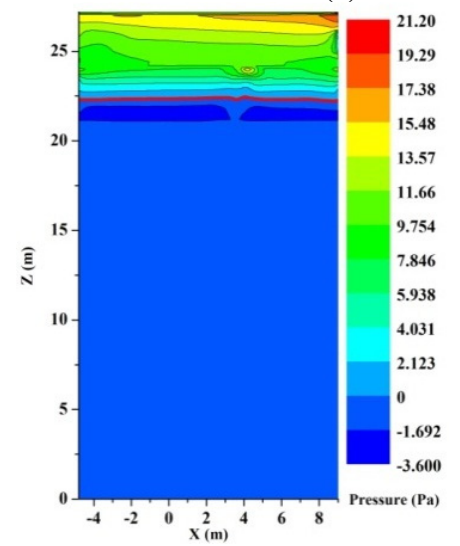

(e)

Fig 4. Pressure contour at middle planewhenfire on (a) Floor 1;(b) Floor 2; (c) Floor 3. (d) Floor 7; (e) Floor 8 
In order to accurately observe the change of neutral plant height under different cases, the accurate heights of neutral plane are shown in the Fig 5.

From the Fig.5, it is can be found that when the height of fire $\left(\mathrm{h}_{\mathrm{f}}\right)$ is lower than the base height $\left(\mathrm{H}_{\mathrm{b}}\right)$, the height of neutral plane just increase slightly with the $h_{f}$ increasing. However, when the $\mathrm{h}_{\mathrm{f}}$ higher than the $\mathrm{H}_{\mathrm{b}}$, the height of neutral plane increase significantly with the $h_{f}$ increasing. Therefore, the $\mathrm{H}_{\mathrm{b}}$ can be the critical value to analyze the influence of fire position on the height of neutral plane. Additionally, it is can be observed that when $h_{f}$ is higher than $\mathrm{H}_{\mathrm{b}}$, the position of neutral plane will be on the same level as that of the fire soucrce. This conclusion can be used to roughly determine the height of neutral plane when the fire postion is higher than the base height.

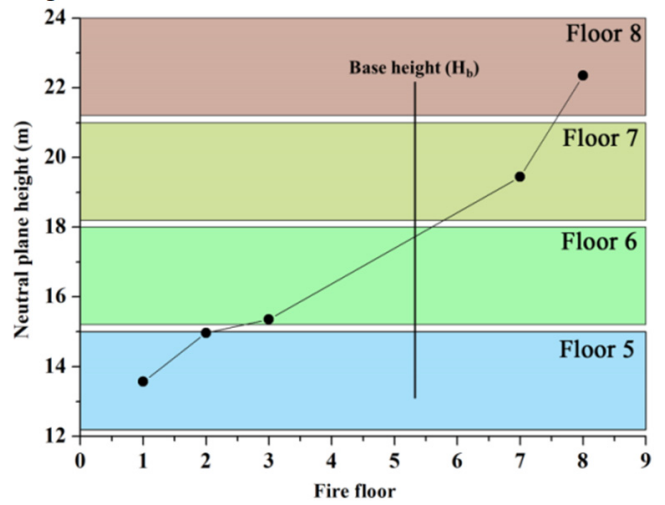

Fig 5. The height of neutral plane under various fire positions.

\section{Conclusion}

In this study, a set of CFD simulations using FDS were carried out to study the influence of fire position on the neutral plane height for inner corridor building with multiple openings. Results show that the influence of fire position on the height of neutral plane can be divided into two phases and the base height $\mathrm{H}_{\mathrm{b}}$ is the critical values for the two phases. When the height of fire is lower than the base height, namely $h_{f}<H_{b}$, with the height of fire increasing, the neutral plane height increase is not significant and the positon of that almost unchange. However, when the height of fire is higher than the base height, namely $h_{f}>H_{b}$, with the fire height increasing, the neutral plane height increase significantly. And in this condition, the position of neutral plane will be on the same level as that of the fire soucrce.

\section{Acknowledgements}

This research was supported by Research Project of Hubei Provincial Department of Education under Grant No.B2019333 and Scientific Research Program of Hubei Business College under Grant No. KY201810.

\section{References}

1. The Skyscraper Centre, The Global Tall Building Database of the CTBUH. [Online], Available: http://skyscrapercenter.com, Last accessed on August 5th,(2019).

2. Hietaniemi J , Kallonen R, Mikkola E . Burning characteristics of selected substances: Production of heat, smoke and chemical species. Fire and Materials, 23,4 (1999).171-185.

3. Li, L.J., et al., Experimental investigation on the characteristics of buoyant plume movement in a stairwell with multiple openings. Energy and Buildings,. 68 (2014). 108-120.

4. J.H. Klote, J.A. Milke, Principles of Smoke Management, ASHRAE/SFPE, Atlanta,GA, USA/Boston, MA, USA, (2002).

5. Zhang J Y, Lu W Z, Huo R, et al. A new model for determining neutral-plane position in shaft space of a building under fire situation. Building and Environment 43,7, (2008), 1101-1108.

6. Xu X.Y,Li Y Z, Mao $\mathrm{S} H$ et al. Model for Neutral-Plane Location in Shaft in Fire. Journal of Combustion Science and Technology, , 17, 4 (2011), 375-381.

7. Mao S H, Li Y Z, Yang L Z et al. Calculation model of critical smoke exhaust rate to suppress overflow based on the neutral plane. Journal of Safety and Environment. 13,1,(2013),203-207.

8. MCGRATTAN K, FORNEY G. Fire dynamics simulator user's guide . Gaithersburg: NIST, (2013).

9. Zhang, W., Hamer, A., Klassen, M. et al.. Turbulence statistics in a fire room model by large eddy simulation. Fire Safety Journal.37 (2002).10-18.

10. Luo, N., et al., An experiment and simulation of smoke confinement and exhaust efficiency utilizing a modified Opposite Double-Jet Air Curtain. Safety Science, 55 (2013). 17-25. 